\title{
Bond Mutual Funds vs. Bond Exchange Traded Funds: Evaluation of Risk Adjusted Performance
}

\author{
Jelena Stankevičienè *(i) and Ieva Petronienè * \\ Department of Financial Engineering, Vilnius Gediminas Technical University, LT-10223 Vilnius, Lithuania \\ * Correspondence: jelena.stankeviciene@vgtu.lt (J.S.); ieva.petroniene@stud.vgtu.lt (I.P.)
}

Received: 18 November 2018; Accepted: 27 March 2019; Published: 2 April 2019

\begin{abstract}
Growing acceptance of passive bond exchange traded funds (ETFs) and actively managed bond mutual funds has exposed the need to find a divide between these two comparatively similar types of instrument. This paper provides a comparative analysis of actively managed bond funds and passive bond ETFs in the context of multiple criteria. The research of risk-adjusted performance of a sampled group of bond funds and ETFs using the TOPSIS multi-criteria decision-making method revealed that actively managed bond funds have a modest advantage over passive bond ETFs. Moreover, the final findings indicate the funds' performance dependability on portfolio composition by fixed income sector.
\end{abstract}

Keywords: exchange traded funds (ETF); risk; performance; bonds; TOPSIS

\section{Introduction}

Stable investment performance and ability to manage risks are the key areas for every investor. Nowadays, financial markets are able to suggest various ways to achieve this. One of the most widely accepted choices is fixed-income instruments. While bonds are considered as a more conservative option, bond exchange traded funds (ETFs) and mutual funds are becoming more and more popular among risk-averse investors who include these instruments in their portfolios for rebalancing, hedging or liquidity enhancement purposes. However, growing acceptance of bond ETFs and mutual funds has exposed the need to find a divide between these two comparatively similar types of instrument.

In general, ETF is a basket of securities traded on exchange like stocks. ETFs track an index in order to replicate the risk and return characteristics of it. Bond ETFs exclusively invests in bonds. Investors are provided with the broad access to bonds without having to select them individually. Generally, bond ETFs are the products of the 21st century and their release can be related to the modernization of fixed-income markets. Mutual funds have been in the marketplace since the 1980s and still have growing numbers-from 88,525 regulated open-end funds worldwide in 2008 to 110,271 funds in 2016 (Statista 2017). Similar, to bond ETF, the bond mutual fund can be described as a managed pool of investments that invests into various bonds or debt securities. Both definitions are parallel, thus making the process of finding a distinction between these two investment vehicles even more complex and relevant.

Return and risk aspects of fixed-income instruments are also a core part. Bond instruments usually take an important role in portfolio enhancement programs. Stable returns and limited risk profile attract investors who seek to hedge, rebalance or increase a liquidity of their portfolios. Generally, bond investments are broadly known to represent lower risk than, for example, stocks as they tend to be less sensitive to most macro threats. However, investing in individual bonds, especially for non-professional investors, can be a challenging task as there is a constant need to manage the maturity dates, research and monitor the financial stability of the issuer, track coupon payments, etc. In addition, the initial investment amount for a diversified bond portfolio is required to be much higher. Thus, 
bond ETFs and bond mutual funds can be a comprehensive alternative. There is a predominant perception that bond mutual funds represent better risk-adjusted performance. One of the main reasons for this belief is the fact that bond mutual funds are mostly actively managed with active managers who are seeking to outperform the relevant benchmark. On the contrary, bond ETFs are usually passively managed instruments meaning that the fund's strategy is designed to match the performance of a particular index, not to produce higher returns. However, there is no recent scientific evidence that actively managed bond mutual funds produce better risk-adjusted performance than passively managed bond ETFs.

There is a visible lack of comparative research on bond ETFs and bond funds. Hence, to address this gap the problem of the research is focused on how risk-adjusted performance may differ according to the elected bond instruments-bond ETFs and bond funds. In response to this issue, the following hypothesis was proposed: passively managed bond ETFs represent better risk-adjusted performance than actively managed bond funds. The aim of the research was to use multi-criteria decision models to evaluate which bond instruments-bond ETFs, or bond funds-represent better risk-adjusted performance. Comparative analysis, statistical analysis, and risk performance ratio calculations were used to test the credibility of the hypothesis.

\section{Theoretical Background}

Since the inception of ETFs, they have become a comprehensive alternative for mutual funds. Not surprisingly, because by its nature, ETFs were designed to unite both simplicity and low costs of index mutual funds with the flexibility of individual stocks. There are a number of studies which compare ETFs and mutual funds (Blake et al. 1993; Guedj and Huang 2009; Rompotis 2009; Kostovetsky 2003; Svetina 2010; Agapova 2011). The number one advantage in most research is cost and tax efficiency of ETFs. The main implication of this advantage is the fact that ETFs are exchange traded which means that major infrastructural costs are borne by the broker (Hill et al. 2015). Another source of ETFs' cost advantage is the fact that these instruments do not have redemption fees that are charged on most open-end funds (Ferri 2007). Actively managed mutual funds can cost several times more than trading ETFs. This originates from the fact that actively managed funds require managers' input, research and expertise while passive ETFs simply track their benchmark index. Transparency is another solid advantage of ETFs. ETF portfolios are disclosed and accessible on a daily basis. In contrast, mutual funds are not required to disclose their portfolios on such a frequent basis (Hill et al. 2015). Additionally, ETFs just like stocks can be traded throughout the day while open-ended mutual funds can only be traded at their closing prices. This speciality can be named as both an advantage and disadvantage of ETFs. It gives the investor a trading flexibility and the pricing of shares is continuous and may vary throughout the day. What is more, it empowers investors with the possibility of buying on margin. However, this is also a source of hidden costs of ETFs which is basically determined by bid-ask spread and price deviations from Net Asset Values (NAV). Gastineau (Angel et al. 2016) coducted research to examine how ETF prices can deviate from the NAV. The authors made findings that ETFs full transparency of trading costs could be achieved only by NAV-based trading. In the case of index mutual funds, dividends are reinvested automatically, while index ETFs do not provide investors with such an option. Moreover, managers of actively managed mutual funds attempt to outperform rather than follow the benchmark index. They can also be more successful during periods of decline as they can proactively apply defensive strategies while ETFs are dependable on the benchmark which is highly exposed to the market risk. In contrast with ETFs, mutual funds are traded on NAV and there are no bid/ask spreads.

Nowadays mutual funds and ETFs can be managed in both active and passive management style. However, by general perception, mutual funds are associated with active while ETFs are usually linked with passive management style. Thus, the discussions on which style is more reliable-active versus passive management-have been apparent for decades. There is a perception that active management, which includes human expertise, analytical forecasts and active decisions, can be 
more flexible and react to any fluctuations in the market than in the case of passively managed instruments. However, Vanguard research revealed, that during the period of 1995-2010 approximately $85 \%$ of actively managed funds underperformed their indexes. Another study (Malkiel 2003) also supports these phenomena and gives evidence that more than $70 \%$ of actively managed equity funds in the US performed lower total returns after expenses than the S\&P index. Despite these facts, active management can still be a number one choice during times of rising interest rates. A survey (Inklebarger 2011) of institutional investors revealed that more than $90 \%$ of institutional investors are more likely to invest in actively managed vehicles during periods of a rising rate environment. In comparison with analytical skills, professional management teams and expertise resources that are required for actively managed funds, passively managed instruments simply follow a market index. This results in significantly lower costs and simplicity. Generally, such passively managed funds are successful in liquid markets (i.e., U.S. large-cap) but lower liquidity can lead to difficulties in tracking the index accurately (Raymond 2016). However, Malkiel (2003) in his study highlights that investors are more likely to trust passive indexing strategies rather than active management. In addition, Malkiel's research proves that reliance on past results does not necessarily lead to successful investment strategies.

The most recent research of Baz et al. (2017) that examines the performance of active and passive bond funds and ETFs revealed that actively managed bond ETFs and funds have outperformed passively managed bond funds. In comparison with the case of equity funds and ETFs, similar findings could not be carried out. Only 35\% of actively managed equity funds and ETFs outperformed their benchmark, while $61 \%$ of bond funds and ETFs beat their benchmark indexes over the previous 5 years. Baz et al. (2017) highlight the main reasons why bond and equity funds have different performance results which are: the high number of noneconomic bond investors (central banks, commercial banks, insurance companies), structural differences, benchmark rebalancing peculiarities, and the wide availability of financial derivatives for active managers.

Bond mutual funds by their nature are very similar to bond ETFs. Investors are given the possibility to invest in various sectors of the fixed income market. Some studies consider ETFs as a subgroup of the mutual fund asset class (Sultan 2014). However, the author highlights that, generally, bond mutual funds are exposed to higher expense ratio and management fees, but at the same time, they are more flexible in comparison with ETFs due to the possibility of investing and repositioning its holdings when required. Another finding of Sultan (2014) is the fact that both bond ETFs and mutual funds have more preference to invest in high yield bonds rather than in investment grade bonds. Thomas Kenny in his publication (Kenny 2016) made a comparison of 5-year returns for both bond mutual funds and bond ETFs. Eight out of 12 mutual funds represented higher total returns in comparison with selected bond ETFs. However, it does not necessarily mean that these selected funds exhibited better risk-adjusted performance. which is the key factor of this scientific paper. What it comes to the management style, a number of studies (Lettau and Madhavan 2016; Malkiel 2003; Rompotis 2009) have shown that active investment strategies are less successful in outperforming the benchmark. However, there is still a lack of studies that have investigated risk-adjusted performance of both actively managed mutual funds and passive bond ETFs. To address this deficiency, the research on risk-adjusted performance of bond ETFs and mutual funds is represented in a methodological and practical way in the sections of this paper.

All these scientific examples suggest that mutual fund risk-return performance evaluation can be carried out efficiently by using a multi-criteria approach encompassing and integrating various aspects. There are many standalone measures that can be useful in the analysis process. The analysis revealed that there is a wide list of scientific studies that combine various indicators to evaluate the fund's performance (Agarwal and Mirza 2017; Bhagyasree and Kishori 2016; Ayaluru 2016; Adhav and Chauhan 2015; Jahnavi and Bose 2016; Rani and Hooda 2017). The vast majority of authors use the following ratios to evaluate the risk return profile of the investment: Sharpe ratio (Sharpe 1966), Jensen's alpha (Jensen 1968), Modigliani-Modigliani, standard deviation. To test the performance 
Jaksic, Lekovic and Milanovic (Jaksic et al. 2015) used the Sharpe ratio, Treynor ratio, and Jensen's Alpha index. Researchers concluded that both the Sharpe and Treynor ratios, when analysed separately, did not represent significant results. However, in combination with other measures, such as Jensen's alpha, more valid results could be achieved. This opinion was also supported by other researchers (Agussalim et al. 2017; Kumara 2016). For that reason, Sharpe and Jensen's alpha were included in the proposed model. Beta as the reflection of systematic or non-diversifiable risk (Tofallis 2008) and Modigliani-Modigliani ratio (Modigliani and Modigliani 1997) that evaluates the annualised risk adjusted performance of a portfolio in relation to the market benchmark were also included in order to represent the complex view of risk adjusted performance. Additional measures-average monthly return and expense ratio-were included in the list due to its primary relevance in the investment selection process. Liu, Rekkas and Wong (Liu et al. 2012) examined Sharpe ratio usage for evaluating fund performance. The authors emphasized that in the cases when returns are asymmetric, the Sharpe ratio may not accurately describe the fund's performance. The main reason for that is the fact that skewness and kurtosis are not captured by the ratio. Consequently, authors also support the idea that the best way to address this issue is to use the complex list of various risk return measures.

Another important study (Bhattacharya et al. 2016) that mainly focuses on Exchange Traded Funds' performance also provides solid scientific justification for the importance of multi-criteria evaluation of the risk return profile of a fund. Authors compare the portfolio performance of exchange traded funds and examine raw as well as risk adjusted returns in the context of five different risk factors: the mean of the return, the standard deviation of returns, the Jensen's alpha, and the unsystematic variance share. According to authors, comprehensive results can be gained only by evaluating a list of factors.

There are many standalone measures to evaluate the risk-return profile of the investment vehicle. However, the single ratio, whichever is chosen, does not have the power to reflect the overall context. Despite the fact that all these studies support the need for multi-criteria evaluation, all research papers suggest calculations and models that can be difficult or time consuming to use for the average investor. Hence, the need to find more simplified guidelines for evaluation of fund performance, arise. For that reason, the practical part is here concentrated on the proposal of the multi-criteria evaluation model using various selected risk return measures and applying multi-criteria decision making technique. The main idea behind the testing of the hypothesis of this research is to compare the risk-adjusted performance of both actively managed bond mutual funds and passive bond ETFs. Probably the best solution to this issue can be the complex evaluation model that comprises the list of the various measures. To test the hypothesis the Multi-Criteria Decision-Making Method (MCDM) was chosen. Another important step of the TOPSIS method is the determination of alternatives. As the core part of this research is fixed income passively managed ETFs and actively managed mutual funds, alternatives could be chosen only from this particular bond asset class group.

\section{Data and Methodology}

\subsection{Multi-Criteria Decision Making Technique}

As the main focus is paid to construction of the model, the primary task is to choose the particular multi criteria decision making model. Multi-Criteria Decision Method (MCDM) is a valuable tool that can be applied to many complex decisions. It facilitates the process of solving problems related to the choices among different alternatives. Generally, MCDM techniques are useful as they help to choose options in the case of discrete problems. In order to apply the multi-criteria method, the following steps are required to be implemented:

- $\quad$ establishment of the list of evaluation criteria;

- identification of the alternatives;

- evaluation of each alternative according to the list of criteria;

- application of the selected MCDM method or methods; 
- $\quad$ selection of the optimal alternative.

There are many MCDM methods that can be applied to the various types of scientific problems. Nevertheless, the Technique for Order Preference by Similarity to the Ideal Solution (TOPSIS) is selected for this research paper due to the flexibility and ease of applicability. Therefore, the method is widely used (Matić et al. 2019; Turskis et al. 2019; Davoudabadi et al. 2019; Hatefi and Tamošaitiene 2019; Zavadskas et al. 2018; Zeng and Xiao 2018; Mardani et al. 2016) by decision-makers to rank the variety of alternatives estimated on a group of conflicting and disproportionate criteria. The idea of the TOPSIS method is that it selects the alternative which is closest to the best choice and farthest from the negative best alternative (Hwang and Yoon 1981). The method helps theoretically ascertain the highest (mostly desirable) and the lowest (mostly avoidable) values for all criteria. According to Hung and Chen (2009) the main advantages of TOPSIS are as follows:

- simple and rational concept;

- comparatively easy calculations;

- $\quad$ ability to measure the relative performance for each alternative.

The primary step when using the TOPSIS method is the formation of the decision matrix which represents the values of criteria with each alternative. Then the matrix must be normalized and values multiplied by the criteria weights. The classical Formula (3) for normalization is used in this research:

$$
\widetilde{r_{i j}}=\frac{r_{i j}}{\sqrt{\sum_{j=1}^{n} r_{i j}^{2}}}
$$

where: $\widetilde{r_{i j}}$-normalized value; $r_{i j}$-value of $i$ criterion of $j$ alternative.

The next step is to find the ideal positive (2) and ideal negative (3) values for each criterion.

$$
V^{*}=\left\{V_{1}^{*}, V_{2}^{*}, \ldots, V_{m}^{*}\right\}=\left\{\left(\max _{j} \omega_{i} \widetilde{r_{i j}}\right),\left(\min _{j} \omega_{i} \widetilde{r_{i j}}\right)\right\}
$$

where: $V^{*}$-maximum value of the criterion; $r_{i j}$-value of $i$ criterion of $j$ alternative; $\omega_{i}$-weight of the criterion $i$.

$$
V^{-}=\left\{V_{1}^{-}, V_{2}^{-}, \ldots, V_{m}^{-}\right\}=\left\{\left(\min _{j} \omega_{i} \widetilde{r_{i j}}\right),\left(\max _{j} \omega_{i} \widetilde{r}_{i j}\right)\right\},
$$

where: $V^{-}$-minimum value of the criterion; $r_{i j}$-value of $i$ criterion of $j$ alternative; $\omega_{i}$-weight of the criterion $i$.

After ideal solutions are found, the distances to the best and the worst criteria can be calculated using Formulas (4) and (5).

$$
D_{j}^{*}=\sqrt{\sum_{i=1}^{m}\left(\omega_{i} \widetilde{r_{i j}}-V_{i}^{*}\right)^{2}},
$$

where: $D_{j}^{*}$-the best alternative; $\omega_{i}$-weight of the criterion $i ; \widetilde{r_{i j}}$-transformed value of the criterion $i$ for alternative $j ; V_{i}^{*}$-maximum value of criterion $i$

$$
D_{j}^{-}=\sqrt{\sum_{i=1}^{m}\left(\omega_{i} \widetilde{r_{i j}}-V_{i}^{-}\right)^{2}},
$$

where: $D_{j}^{-}$-the worst alternative; $\omega_{i}$-weight of the criterion $i ; \widetilde{r_{i j}}$-transformed value of the criterion $i$ for alternative $j ; V_{i}^{-}-$minimum value of criterion $i$.

The final step in TOPSIS method calculations is to find the cumulative criterion (6). The larger the value $C_{j}^{*}$, the better.

$$
C_{j}^{*}=\frac{D_{j}^{-}}{D_{j}^{*}+D_{j}^{-}},(j=1,2, \ldots, n)\left(0 \leq C_{j}^{*} \leq 1\right),
$$


where: $C_{j}^{*}$-cumulative criterion; $D_{j}^{-}$-the worst alternative; $D_{j}^{*}$ - the best alternative.

The inseparable part of any MCDM method is the formation of the list of criteria (Ginevičius and Podvezko 2008). After the identification of the list of criteria, it is essential to estimate the importance of each criterion. The opinions of experts are used to set the weights for each of the criteria. The weights can be set using the direct method which simply takes an average weighting of each expert for each criterion. Another important aspect is to test the level of agreement and statistical significance of the opinions of the experts. Thus, Kendall's coefficient of concordance was calculated using Formula (7):

$$
W=\frac{12 S^{2}}{r^{2}\left(m^{2}-m\right)}
$$

where: $S^{2}$ - the sum of squared deviations; $r$-number of experts; $m$-number of criteria.

Generally, the coefficient can deviate in the range from 0 to 1 . Coefficient 0 means that there is no agreement between the opinions of experts, while 1 indicates perfect agreement. To measure the statistical significance of the coefficient of concordance the $X^{2}$ criterion must be calculated using the formula:

$$
X^{2}=W r(m-1),
$$

where: $W$-coefficient of concordance; $m$-number of criteria; $r$-number of experts

The $X^{2}$ criterion is distributed with $v=(m-1)$ degrees of freedom. If the calculated value of $X^{2}$ is greater than the critical value of $X^{2}$ then there is an agreement between the experts. If the $X^{2}$ value is greater than the critical value of $X^{2}$, it means that there is an agreement between the opinions of experts and the significance of concordance is acceptable. This means that weights can be used for applying the TOPSIS method.

\subsection{List of Criteria}

The research on scientific literature highly contributes to the process of criteria selection. A review on recent literature revealed that classical measures of risk adjusted performance, such as Sharpe ratio, Jensen's alpha, Treynor ratio, remain actual and useful. Despite the fact that return or risk as standalone measures still play an important role in a decision-making process, many authors agree that the comparative analysis of funds can be better evaluated by using the risk return relationship rather than a single measure. Another important finding is the fact that a multi-criteria approach is needed to get more significant and valid results. The investigation of one ratio itself can be misleading. However, in conjunction with other risk return measures, findings can be more informative. Hence, for the practical part the following measures were selected: Sharpe ratio, beta, Jensen's alpha, Modigliani-Modigliani ratio, standard deviation. Literature analysis supported the credibility of these ratios. The list of criteria (Table 1) is the core part of the TOPSIS technique. All the selected criteria determine the scope in which the alternatives will be evaluated. 
Table 1. The proposed list of criteria with description (compiled by authors).

\begin{tabular}{|c|c|c|c|}
\hline & Criteria & Formula & Description \\
\hline \multirow{5}{*}{ Risk-return measures } & Sharpe ratio & $S_{R}=\frac{R i-R_{f}}{\sigma(R i)}$ & $\begin{array}{l}\text { Evaluates reward per } \\
\text { unit of risk using } \\
\text { standard deviation and } \\
\text { excess returns }\end{array}$ \\
\hline & Beta & $\left.\beta=\frac{\operatorname{cov}\left(r_{i}, r_{m}\right)}{\operatorname{var}\left(r_{m}\right)}\right)$ & $\begin{array}{l}\text { Evaluates systematic or } \\
\text { non-diversifiable risk }\end{array}$ \\
\hline & Jensen's alpha & $\begin{array}{c}\alpha_{J}= \\
R_{i}-\left(R_{f}+\beta\left(R_{m}-R_{f}\right)\right.\end{array}$ & $\begin{array}{l}\text { Evaluates how much } \\
\text { extra return a fund has } \\
\text { earned above the } \\
\text { expected return }\end{array}$ \\
\hline & $\begin{array}{l}\text { Modigliani-Modigliani } \\
\left(M^{2}\right)\end{array}$ & $M^{2}=\left(R_{i}-R_{f}\right) \frac{\sigma_{m}}{\sigma_{i}}+r_{f}$ & $\begin{array}{l}\text { Evaluates the annualised } \\
\text { risk adjusted } \\
\text { performance of a } \\
\text { portfolio in relation to } \\
\text { the market benchmark }\end{array}$ \\
\hline & Standard Deviation & $\sigma=\sqrt{\frac{\sum_{t=1}^{n}\left(R_{t}-\mu\right)^{2}}{n-1}}$ & $\begin{array}{l}\text { Evaluates the historical } \\
\text { volatility of returns }\end{array}$ \\
\hline \multirow{2}{*}{+} & \multicolumn{3}{|c|}{ Average Monthly Return } \\
\hline & \multicolumn{3}{|c|}{ Expense Ratio } \\
\hline
\end{tabular}

Hence, the final list of alternatives is represented in Table 1 . There are five calculated ratios (Sharpe, Beta, Jensen's alpha, $M^{2}$, standard deviation) and two standalone measures. Table 2 represents the types of criteria. The majority of indicators are maximising. Only two criteria are minimising: standard deviation and expense ratio.

Table 2. Types of criteria (compiled by authors).

\begin{tabular}{cccccccc}
\hline Criteria & $\begin{array}{c}\text { Sharpe } \\
\text { Ratio }\end{array}$ & $\boldsymbol{\beta}$ & $\begin{array}{c}\text { Jensen's } \\
\text { Alpha }\end{array}$ & $\boldsymbol{M}^{2}$ & $\boldsymbol{\sigma}$ & $\begin{array}{c}\text { Avg } \\
\text { month } \\
\text { Return }\end{array}$ & $\begin{array}{c}\text { Expense } \\
\text { Ratio }\end{array}$ \\
\hline Type & $\max$ & $\max$ & $\max$ & $\max$ & $\min$ & $\max$ & $\min$ \\
\hline
\end{tabular}

Consequently, the greater the value of maximising criteria the better the performance is exhibited. The lower the deviation the less risky is the investment and the lower the expense ratio the higher the returns expected.

\subsection{Data}

As it is complicated to evaluate the entire list of bond funds and ETFs using the TOPSIS method, the sample group of five actively managed bond mutual funds and five passively managed bond ETFs were selected to form the list of alternatives. Hence, a list of 10 alternatives is proposed. Selection of a sample group of funds is based on the following factors:

- mutual funds/ETFs operating time (for monthly returns the period of 2015-01-2017-10 is taken);

- mutual funds/ETFs provider (various providers);

- mutual funds/ETFs asset class (fixed income only).

The U.S. three months Treasury bill is used as a risk-free instrument which has no credit risk, and the maturity is so short that there is no liquidity or market risk. Bloomberg Barclays US Aggregate Bond TR USD index performance is used to introduce the performance of the market. 
Hence, the following bond ETFs and mutual funds comprise the list of alternatives used for implementing the TOPSIS method and are represented in Table 3.

Table 3. List of alternatives (source: compiled by authors).

\begin{tabular}{ccl}
\hline Type & Short Name & \multicolumn{1}{c}{ Full Name } \\
\hline ETF & HYG & iShares iBoxx \$ High Yield Corporate Bond ETF \\
ETF & VCIT & Vanguard Intermediate-Term Corporate Bond ETF \\
ETF & TOTL & The SPDR ${ }^{\circledR}$ DoubleLine ${ }^{\circledR}$ Total Return Tactical ETF \\
ETF & AGGY & WisdomTree Barclays Yield Enhanced U.S. Aggregate Bond Fund ETF \\
ETF & ZPRC & SPDR Thomson Reuters Global Convertible Bond UCITS ETF \\
Mutual Fund & VBLTX & Vanguard Long-Term Bond Index Fund Investor Shares \\
Mutual Fund & VFIRX & Vanguard Short-Term Treasury Fund Admiral Shares \\
Mutual Fund & MSYPX & Morgan Stanley Institutional Fund Trust High Yield Portfolio Class A \\
Mutual Fund & CBRAX & JPMorgan Corporate Bond Fund Class A \\
Mutual Fund & VGIVX & Vanguard Emerging Markets Government Bond Index Fund \\
& & Institutional Shares \\
\hline
\end{tabular}

After the identification of the list of criteria, it is essential to estimate the importance of each criterion. To address this task, a questionnaire containing risk-adjusted performance dimensions and indicators (presented previously) was designed and sent to seven non-professional investors. Their evaluations are represented as the opinions of experts and are used to set the weights for each of the criteria. The weights are set using the direct method which simply takes an average weighting of each expert for each criterion. The results are represented in Table 4. The most important criterion according to the experts is the Sharpe ratio. The expense ratio, average monthly return and standard deviation can be also considered as significant criteria.

Table 4. Final weights set by the experts (Source: compiled by authors).

\begin{tabular}{ccccccccccc}
\hline \multirow{2}{*}{ Criteria } & \multicolumn{10}{c}{ Experts } \\
\cline { 2 - 11 } & $\mathbf{1}$ & $\mathbf{2}$ & $\mathbf{3}$ & $\mathbf{4}$ & $\mathbf{5}$ & $\mathbf{6}$ & $\mathbf{7}$ & SUM & Weight Rank \\
\hline Sharpe ratio & 0.30 & 0.35 & 0.20 & 0.20 & 0.30 & 0.45 & 0.30 & 2.10 & 0.300 & 1 \\
$\beta$ & 0.10 & 0.10 & 0.05 & 0.05 & 0.20 & 0.00 & 0.05 & 0.55 & 0.079 & 5 \\
Jensen's Alpha & 0.00 & 0.05 & 0.10 & 0.05 & 0.00 & 0.00 & 0.05 & 0.25 & 0.036 & 7 \\
M $^{2}$ & 0.05 & 0.10 & 0.00 & 0.05 & 0.00 & 0.10 & 0.05 & 0.35 & 0.050 & 6 \\
$\sigma$ & 0.20 & 0.05 & 0.10 & 0.10 & 0.20 & 0.10 & 0.20 & 0.95 & 0.136 & 4 \\
avg mnth return & 0.20 & 0.00 & 0.25 & 0.30 & 0.20 & 0.10 & 0.20 & 1.25 & 0.179 & 3 \\
Expense ratio & 0.15 & 0.35 & 0.30 & 0.25 & 0.10 & 0.25 & 0.15 & 1.55 & 0.221 & 2 \\
SUM & 1.00 & 1.00 & 1.00 & 1.00 & 1.00 & 1.00 & 1.00 & 7.00 & 1.00 & - \\
\hline
\end{tabular}

To test the level of agreement and the statistical significance of the opinions of the experts Kendall's coefficient of concordance was calculated. The coefficient of concordance of the dataset (Table 4) is 0.56 . Generally, the coefficient can deviate in the range from 0 to 1 . Coefficient 0 means that there is no agreement between the opinions of experts, while 1 indicates perfect agreement. Hence, the value of 0.56 means that there is a moderate agreement between the experts. To measure the statistical significance of the coefficient of concordance the $X^{2}$ criterion was calculated. The $X^{2}$ criterion is distributed with $v=(m-1)$ degrees of freedom. If the calculated value of $X^{2}$ is greater than the critical value of $X^{2}$ then there is an agreement between the experts. Results show that the $X^{2}$ value for the weights is 23.43. The critical value of $X^{2}$ with the degree of freedom 6 and probability of 0.05 is equal to 12.59 . As $X^{2}$ value is greater than the critical value of $X^{2}(23.43>12.59)$ it means that there is an agreement between the opinions of experts and the significance of concordance is acceptable. Hence, weights represented in Table 4 can be used for applying the TOPSIS method presented in the practical part of the research. 
Consequently, as the data selection, the method used, the opinion of experts, and the weights are relevant and acceptable for further investigation and practical calculations while the results are represented in the next section of this paper.

\section{Risk-Adjusted Performance Evaluation and Results}

As it was mentioned before, the TOPSIS method was chosen to test the credibility of the hypothesis of this research. Table 5 represents the primary decision matrix of values for each criterion and alternative. The process of construction of the decision matrix and determination of weights is considered as the first step in the implementation of the TOPSIS method.

Table 5. Values of criteria of risk-adjusted performance of selected bond ETFs and mutual funds (source: compiled by authors).

\begin{tabular}{|c|c|c|c|c|c|c|c|c|c|c|c|}
\hline \multirow[b]{2}{*}{ Criteria } & \multirow[b]{2}{*}{ Weights } & \multicolumn{10}{|c|}{ ETFs \& Funds } \\
\hline & & VBLTX & VFIRX & MSYPX & CBRAX & VGIVX & HYG & VCIT & TOTL & AGGY & ZPRC \\
\hline Sharpe ratio & 0.300 & 0.007 & -1.387 & 0.046 & -0.068 & 0.086 & 0.003 & -0.077 & -0.407 & -0.167 & -0.091 \\
\hline$\beta$ & 0.079 & 2.619 & 0.324 & 0.189 & 1.154 & 1.371 & 0.430 & 1.287 & 0.780 & 1.229 & -1.188 \\
\hline Jensen's Alpha & 0.036 & 0.698 & -0.331 & 0.124 & 0.229 & 0.491 & 0.120 & 0.252 & -0.059 & 0.155 & -0.536 \\
\hline $\mathrm{M}^{2}$ & 0.050 & 0.483 & -0.596 & 0.513 & 0.425 & 0.544 & 0.480 & 0.418 & 0.162 & 0.348 & 0.407 \\
\hline$\sigma$ & 0.136 & 2.118 & 0.300 & 1.604 & 1.069 & 1.536 & 1.610 & 1.093 & 0.646 & 0.995 & 2.494 \\
\hline avg mnth return & 0.179 & 0.492 & 0.062 & 0.552 & 0.405 & 0.610 & 0.480 & 0.394 & 0.214 & 0.312 & 0.252 \\
\hline Expense ratio & 0.221 & 0.050 & 0.100 & 1.020 & 0.750 & 0.290 & 0.490 & 0.070 & 0.550 & 0.120 & 0.500 \\
\hline
\end{tabular}

According to the opinion of experts, the most important criteria are Sharpe ratio and expense ratio. The following criterion (expense ratio) is not considered as a measure of risk-adjusted performance. However, its significance for investors in the decision-making process is undeniable. Hence, it was decided to leave this indicator in the final list of criteria. The best Sharpe ratio is represented bythe VGIVX (0.086) mutual fund. It suggests that the return of this fund is adequate for the risk taken. VBLTX (0.007) and MSYPX (0.046) bond funds also have positive Sharpe ratios. The remaining alternatives represent negative reward to volatility. However, when taking into account Jensen's alpha measure, eight out of 10 funds are shown to be positive which means that these funds can earn more than expected in the context of systematic risk taken. Another insight from the primary matrix of the criteria values (Table 5) is the fact that all funds have positive monthly average returns. However, when comparing with the average monthly returns of the benchmark index (Bloomberg Barclays US Aggregate Bond TR USD) and the risk-free instrument (U.S. 3 months Treasury bill), the results are controversial.

All funds (except VFIRX mutual fund and TOTL ETF) performed better than the benchmark index (average monthly return $0.22 \%$ ) during the sample period. In comparison with the risk-free instrument, which had an average monthly return of $0.48 \%$, only four funds (three bond mutual funds and one ETF) exhibited higher average returns. What it comes to the expense ratios of the selected alternatives, results also vary greatly. The sample group of selected bond funds and ETFs evidence that the perception about the fact that mutual funds have generally higher expense ratios than ETFs can be misleading. It is visible that the lowest expense ratio is represented by the bond mutual fund VBLTX. Only one fund MSYPX stands out with a significantly higher expense ratio than that of the others.

Subsequently, it is difficult to make unambiguous conclusions when analysing alternatives on a standalone criteria basis. For example, one alternative can be exclusively good in the context of one particular criterion, however, it can underperform other criteria, which can be the same or even more important. In such cases, MCDM methods can eliminate or ease the process of such decision making.

The following important step required for the implementation of the applied method is the calculation of the weighted normalized decision matrix. The primary decision matrix contains values that are measured in different units. 
For comparison reasons, values must be transformed into a non-dimensional scale. Such normalization can be done by using the Formula (1). Normalized and weighted values of the matrix are represented in Table 6.

Table 6. Weighted normalized values of criteria of selected bond ETFs and mutual funds (source: compiled by authors).

\begin{tabular}{ccccccccccccc}
\hline \multicolumn{10}{c}{ ETFs and Funds } \\
\hline Criteria & Weights & VBLTX & VFIRX & MSYPX CBRAX & VGIVX & HYG & VCIT & TOTL & AGGY & ZPRC \\
\hline Sharpe ratio & 0.300 & 0.001 & -0.284 & 0.010 & -0.014 & 0.018 & 0.001 & -0.016 & -0.083 & -0.034 & -0.019 \\
$\beta$ & 0.079 & 0.052 & 0.006 & 0.004 & 0.023 & 0.027 & 0.009 & 0.026 & 0.016 & 0.025 & -0.024 \\
Jensen's Alpha & 0.036 & 0.022 & -0.010 & 0.004 & 0.007 & 0.015 & 0.004 & 0.008 & -0.002 & 0.005 & -0.017 \\
$\mathrm{M}^{2}$ & 0.050 & 0.017 & -0.021 & 0.018 & 0.015 & 0.019 & 0.017 & 0.015 & 0.006 & 0.012 & 0.014 \\
$\sigma$ & 0.136 & 0.061 & 0.009 & 0.046 & 0.031 & 0.044 & 0.047 & 0.032 & 0.019 & 0.029 & 0.072 \\
avg mnth return & 0.179 & 0.068 & 0.009 & 0.076 & 0.056 & 0.084 & 0.067 & 0.054 & 0.03 & 0.043 & 0.035 \\
Expense ratio & 0.221 & 0.007 & 0.014 & 0.143 & 0.105 & 0.041 & 0.069 & 0.01 & 0.077 & 0.017 & 0.070 \\
\hline
\end{tabular}

After normalization was performed the positive $\left(\mathrm{V}^{*}\right)$ and negative $\left(\mathrm{V}^{-}\right)$ideal solutions for each criterion were calculated (Table 7). According to the results, the ideal value of the Sharpe ratio is represented by the VGVIX mutual fund, whereas the negative ideal solution by the VFIRX mutual fund. For the Beta criterion, the highest value is represented by VBLTX and the lowest one by ZPRC. For Jensen's alpha criterion the best and the worst values are exhibited by VBLTX and ZPRC respectively. VGIVX and VFIRX are the ideal positive and negative solutions for the $\mathrm{M}^{2}$ criterion. For the standard deviation, the best solution is considered to be VFIRX, while the best negative solution is ZPRC. The best option for average monthly return is VGIVX and the worst is VFIRX. When it comes to expense ratio, VBLTX is the positive ideal solution whereas MSYPX is the negative ideal solution.

Table 7. Positive and negative ideal solutions for each criterion (source: compiled by authors).

\begin{tabular}{cccccccc}
\hline & $\begin{array}{c}\text { Sharpe } \\
\text { Ratio }\end{array}$ & $\boldsymbol{\beta}$ & $\begin{array}{c}\text { Jensen's } \\
\text { Alpha }\end{array}$ & $\mathbf{M}^{2}$ & $\boldsymbol{\sigma}$ & $\begin{array}{c}\text { Avg mnth } \\
\text { Return }\end{array}$ & $\begin{array}{c}\text { Expense } \\
\text { Ratio }\end{array}$ \\
\hline $\mathrm{V}^{*}$ & 0.0177 & 0.0521 & 0.0219 & 0.0190 & 0.0087 & 0.0840 & 0.0070 \\
$\mathrm{~V}^{-}$ & -0.2841 & -0.0236 & -0.0168 & -0.0208 & 0.0721 & 0.0085 & 0.1425 \\
\hline
\end{tabular}

Hence, from first sight it is apparent that the VFIRX bond mutual fund is considered as the best negative solution in the context of three criteria. For the best positive solution, VGVIX fund can be named as the best alternative in the context of three criteria. However, this is only the superficial conclusion and the presumptive findings can only be obtained after the final steps of the applied TOPSIS method.

The separation measures from the positive ideal and the negative ideal solution as well as the ranked criterion of relative closeness to the positive ideal solution are represented in Table 8.

Table 8. Positive and negative ideal solutions for each criterion (source: compiled by authors).

\begin{tabular}{cccccc}
\hline Rank & Type & Name & $\mathbf{D}_{\mathbf{j}}{ }^{*}$ & $\mathbf{D}_{\mathbf{j}}{ }^{-}$ & $\mathbf{C}_{\mathbf{j}}{ }^{*}$ \\
\hline 1 & Fund & VGIVX & 0.06 & 0.34 & 0.86 \\
2 & Fund & VBLTX & 0.06 & 0.33 & 0.85 \\
3 & ETF & VCIT & 0.06 & 0.31 & 0.84 \\
4 & ETF & AGGY & 0.08 & 0.29 & 0.79 \\
5 & ETF & HYG & 0.09 & 0.31 & 0.77 \\
6 & Fund & CBRAX & 0.11 & 0.29 & 0.72 \\
7 & Fund & MSYPX & 0.15 & 0.31 & 0.67 \\
8 & ETF & ZPRC & 0.14 & 0.28 & 0.67 \\
9 & ETF & TOTL & 0.14 & 0.22 & 0.61 \\
10 & Fund & VFIRX & 0.32 & 0.15 & 0.32 \\
\hline
\end{tabular}


The ranked criterion of relative closeness to the positive ideal solution is the core part which allows comparison of the final results. The primary conclusion, that the best alternative is the VGIVX $\left(C_{j}^{*}=0.86\right)$ mutual fund and the worst alternative is VFIRX $\left(C_{j}^{*}=0.32\right)$, can be verified. Generally, the top three alternatives: VGVIX $\left(C_{j}^{*}=0.86\right)$, VBLTX $\left(C_{j}^{*}=0.85\right)$ mutual funds and VCIT $\left(C_{j}{ }^{*}=0.84\right)$ bond ETF show very similar results. According to the portfolio breakdown by fixed income sectors, represented in Table 9, both VGIVX and VBLTX mutual funds have a comparatively similar portfolio composition. Their holdings are focused on the combination of government and corporate bonds. VCIT ETF, which is ranked as the third best alternative, invests mainly in the corporate bonds sector. Another interesting insight is the fact that the worst bond mutual fund from the sample group has a portfolio constructed mainly from government bonds. According to the results, it is apparent that mixed portfolios or portfolios with a concentration in corporate bonds exhibited better performance.

Table 9. Portfolio breakdown by fixed income sector (source: compiled by authors).

\begin{tabular}{|c|c|c|c|c|c|c|c|}
\hline \multirow{2}{*}{ Rank } & \multirow{2}{*}{ Fund/ETF } & \multicolumn{6}{|c|}{ Fixed Income Sectors } \\
\hline & & Government & Corporate & Securitized & Municipal & Cash \& Equivalents & Other \\
\hline 1 & VGIVX & 66.76 & 32.21 & 0.00 & 0.00 & 0.39 & 0.00 \\
\hline 2 & VBLTX & 44.15 & 51.51 & 0.19 & 3.72 & 0.43 & 0.00 \\
\hline 3 & VCIT & 0.20 & 98.77 & 0.41 & 0.00 & 0.62 & 0.00 \\
\hline 4 & AGGY & 18.09 & 49.56 & 32.04 & 0.25 & 0.00 & 0.00 \\
\hline 5 & HYG & 100.42 & 0.00 & 0.00 & 0.00 & -0.53 & 0.00 \\
\hline 6 & CBRAX & 0.26 & 95.15 & 1.03 & 0.00 & 3.56 & 0.00 \\
\hline 7 & MSYPX & 1.04 & 98.47 & 0.00 & 0.00 & 0.16 & 0.00 \\
\hline 8 & ZPRC & 0.72 & 94.11 & 0.00 & 0.00 & 1.87 & 0.00 \\
\hline 9 & TOTL & 17.10 & 17.35 & 57.76 & 0.00 & 5.68 & 2.11 \\
\hline 10 & VFIRX & 94.07 & 0.73 & 0.60 & 0.00 & 4.60 & 0 \\
\hline
\end{tabular}

All things considered, the applied TOPSIS method revealed that actively managed bond mutual funds from the sample group exhibit better results than passive bond ETFs. Thus, the proposed hypothesis that passively managed bond ETFs represents better risk-adjusted performance than actively managed bond funds should be rejected in the context of this research.

However, it cannot be ignored that there are some limitations regarding the final results. First, the findings are very sensitive to the selection of the representative funds/ETFs. It is very plausible that the results could have been different if another list of alternatives had been chosen. Hence, the objective results can only be achieved when investigating the entire list of bond funds and ETFs. Second, the calculated criteria values are sensitive to the selected number of periods and may vary according to the time horizon. For example, it can be a crucial factor for the values of monthly average returns as well as for standard deviations and other risk-adjusted performance ratios.

For further investigation, the following suggestions can be made:

- a comparative analysis of passive and active strategies can be made in the narrowed context. For example, the research can be implemented for the particular funds/ETFs according to their portfolio composition;

- for this research, only one MCDM method (TOPSIS) was applied. Hence, for validation purposes, it can be beneficial to test the hypothesis using several methods.

The analysis can be made in the context of a modified list of criteria. In this research, some measures (expense ratio, monthly average return), that were not considered as risk-adjusted performance metrics, were added with the purpose to extend the list of criteria. Hence, a narrowed or broadened selection of criteria may have an impact on the final findings.

\section{Conclusions}

Bond ETFs and bond mutual funds have both similarities and differences. The main areas of differences are buying and selling, pricing, transparency and taxation whereas similarities arise from 
the fields of diversification, required investment amounts and control. Despite the fact that mutual funds account for many years in the marketplace, ETFs, as a comparatively new way of investing, also have very strong positions among investors. Thus, there are no specific guidelines for which instrument-ETF or mutual fund-is the better option.

In order to compare the list of funds in the context of multiple criteria, the multi-criteria decision-making methods can be a reasonable solution. The applied TOPSIS method revealed that its simple and rational concept, as well as uncomplicated calculations, may effectively allow credible results to be obtained while measuring the relative performance of each alternative.

The proposed hypothesis that passively managed bond ETFs represents better risk-adjusted performance than actively managed bond funds should be rejected in the context of this research. According to the results, the best alternatives are actively managed bond mutual funds $\left(\right.$ VGIVX $\mathrm{C}_{\mathrm{j}}{ }^{*}=$ 0.86 ; VBLTX $\left.\mathrm{C}_{\mathrm{j}}{ }^{*}=0.85\right)$. However, the advantage of actively managed bond funds over passive bond ETFs is comparatively mild.

The results and a final ranking of alternatives suggest that the composition of the portfolio by fixed income sectors can have an impact on the performance of the bond funds/ETFs. The worst results are exhibited by funds which have a large proportion of government bonds in their portfolio (VFIRX $\mathrm{C}_{\mathrm{j}}^{*}=0.32 ; \mathrm{HYG} \mathrm{C}_{\mathrm{j}}{ }^{*}=0.77$ ). Instruments which particularly focus on corporate bonds have moderate

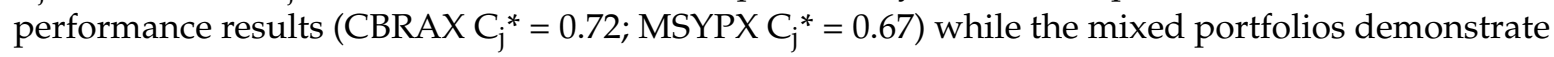
better overall results in the sample group $\left(\right.$ VGIVX $_{\mathrm{j}^{*}}{ }^{*}=0.86$; ${\text { VBLTX } C_{j}{ }^{*}=0.85 ;}$ AGGY $C_{j}{ }^{*}=0.79$ ).

The comparative analysis of actively managed bond funds and passive bond ETFs has some limitations such as findings' sensitivity to the selection of representative funds/ETFs, dependability on the time horizon, and the selection of the list of criteria. Hence, the topic of the paper still remains open for further investigation.

Author Contributions: J.S. and I.P. conceived and designed the experiments, performed the experiments, analysed the data, wrote the paper.

Funding: This research received no external funding.

Conflicts of Interest: The authors declare no conflict of interest.

\section{References}

Adhav, Sunil M., and Pratap M. Chauhan. 2015. Comparative Study of Mutual Funds of Selected Indian Companies. International Journal of Science, Technology \& Management 4: 44-51.

Agapova, Anna. 2011. Conventional mutual index funds versus exchange traded funds. Journal of Financial Markets 14: 323-43. [CrossRef]

Agarwal, Shivangi, and Nawazish Mirza. 2017. A study on the risk-adjusted performance of mutual funds industry in India. Review of Innovation and Competitiveness 3: 75-94. [CrossRef]

Agussalim, M., Nandan Limakrisna, and Ali Hapzi. 2017. Mutual Funds Performance: Conventional and Sharia Product. International Journal of Economics and Financial Issues 7: 150-56.

Angel, James J., Todd J. Broms, and Gary L. Gastineau. 2016. ETF Transaction Costs are Often Higher Than Investors Realize. The Journal of Portfolio Management 42: 1-12. [CrossRef]

Ayaluru, Muralidhar Prasad. 2016. Performance Analysis of Mutual Funds: Selected Reliance Mutual Fund Schemes. Parikalpana KIIT Journal of Management 12: 52-62. [CrossRef]

Baz, Jamil, Ravi K. Mattu, James Moore, and Helen Guo. 2017. Bonds Are Different: Active Versus Passive Management in 12 Points. Available online: https://www.pimco.com/en-us/insights/viewpoints/ quantitative-research-and-analytics/bonds-are-different-active-versus-passive-management-in-12-points (accessed on 30 October 2017).

Bhagyasree, N., and Battini Kishori. 2016. A Study on Performance Evaluation of Mutual Funds Schemes in India. International Journal for Innovative Research in Science \& Technology 2: 812-16.

Bhattacharya, Utpal, Benjamin Loos, Steffen Meyer, and Andreas Hackethal. 2016. Abusing ETFs. Review of Finance 17: 1217-50. [CrossRef] 
Blake, Christopher R., Edwin J. Elton, and J. Martin. 1993. The Performance of Bond Mutual Funds. Journal of Business 66: 371-403. [CrossRef]

Davoudabadi, Reza, Seyed Meysam Mousavi, Jonas Saparauskas, and Hossein Gitinavard. 2019. Solving construction project selection problem by a new uncertain weighting and ranking based on compromise solution with linear assignment approach. Journal of Civil Engineering and Management 25: 241-51. [CrossRef]

Ferri, Richard A. 2007. The ETF Book. All You Need to Know about Exchange Traded Funds. Hoboken: John Wiley \& Sons., Inc., 386p, ISBN 78-0-470-13063-6.

Ginevičius, Romualdas, and Valentinas Podvezko. 2008. Multicriteria evaluation of Lithuanian banks from the perspective of their reliability for clients. Journal of Business Economics and Management 9: 257-67. [CrossRef]

Guedj, Ilan, and Jennifer Chunyan Huang. 2009. Are ETFs Replacing Index Mutual Funds. Available online: http:/ / ssrn.com/abstract=1108728 (accessed on 28 October 2017).

Hatefi, Seyed Morteza, and Jolanta Tamošaitienè. 2019. An integrated fuzzy DEMATEL-fuzzy ANP model for evaluating construction projects by considering interrelationships among risk factors. Journal of Civil Engineering and Management 25: 114-31. [CrossRef]

Hill, Joanne M., Dave Nadig, and Matthew Hougan. 2015. A Comprehensive Guide to Exchange-Traded Funds (ETFs). Research Foundation Publications. Charlottetown: CFA Institute, p. 181.

Hung, Chia-Chang, and Liang-Hsuan Chen. 2009. A Fuzzy TOPSIS Decision Making Model with Entropy Weight under Intuitionistic Fuzzy Environment. Paper presented at the International Multi-Conference of Engineers and Computer Scientists IMECS, Hong Kong, China, March 18-20.

Hwang, Ching-Lai, and Kwangsun Yoon. 1981. Multiple Attribute Decision Making: Methods and Applications, A State-of-the-Art Survey. Berlin: Springer, p. 269.

Inklebarger, Timothy. 2011. Institutions Thinking Active but Acting Passive. Pensions \& Investments. Available online: http:/ / www.pionline.com/article/20110502/PRINT/305029909/institutions-thinking-active-butacting-passive (accessed on 30 October 2017).

Jahnavi, and Percy Bose. 2016. Performance evaluation of selected equity based mutual fund schemes: An analysis of risk and return. International Journal of Marketing, Financial Services E Management Research 5: 1-20.

Jaksic, Milena, Miljan Leković, and Marina Milanović. 2015. Measuring the Performance of Mutual Funds-A Case Study. Industrija 43: 37-51. [CrossRef]

Jensen, Michael C. 1968. The Performance of Mutual Funds in the Period 1945-1964. Journal of Finance 23: 389-416. [CrossRef]

Kenny, Thomas. 2016. Bond ETFs vs. Bond Mutual Funds: Historical Returns and Costs. The Balance. November. Available online: https:/ / www.thebalance.com/bond-etfs-mutual-funds-416946 (accessed on 30 October 2017).

Kostovetsky, Leonard. 2003. Index mutual funds and exchange-traded funds. Journal of Portfolio Management 29: 80-92. [CrossRef]

Kumara, R. Naveen. 2016. Gold Etfs vs. Equity Etfs: Comparative Analysis of Their Performance. International Journal of Social Sciences and Management 3: 222-27. [CrossRef]

Lettau, Martin, and Ananth Madhavan. 2016. ETF 101 For Economists. Available online: faculty.haas.berkeley. edu/lettau/papers/ETF.pdf (accessed on 30 September 2017).

Liu, Ying, Marie Rekkas, and Augustine Wong. 2012. Inference for the Sharpe Ratio Using a Likelihood-Based Approach. Journal of Probability and Statistics 2012: 1-24. [CrossRef]

Malkiel, Burton G. 2003. Passive Investment Strategies and Efficient Markets. European Financial Management 9: 1-10. [CrossRef]

Mardani, Abbas, Ahmad Jusoh, Edmundas Kazimieras Zavadskas, Norhayati Zakuan, Alireza Valipour, and Mansooreh Kazemilari. 2016. Proposing a new hierarchical framework for the evaluation of quality management practices: A new combined fuzzy hybrid MCDM approach. Journal of Business Economics and Management 17: 1-16. [CrossRef]

Matić, Bojan, Stanislav Jovanović, Dillip Kumar Das, Edmundas Kazimieras Zavadskas, Željko Stević, Siniša Sremac, and Milan Marinković. 2019. A New Hybrid MCDM Model: Sustainable Supplier Selection in a Construction Company. Symmetry 11: 353. [CrossRef]

Modigliani, Franco, and Leah Modigliani. 1997. Risk-Adjusted Performance. Journal of Portfolio Management 23: 45-54. [CrossRef] 
Rani, Geeta, and Vijay Singh Hooda. 2017. Performance Evaluation of Mutual Fund Schemes: A Study of Selected Topper Schemes. Journal of Business and Management 19: 1-6.

Raymond, James. 2016. Active and Passive Investing in Bull, Bear and Neutral Markets. Available online: https://www.raymondjames.com/-/media/rj/dotcom/files/corporations-and-institutions/relatedservices/institutional-consulting-services/ams_activepassive_white_paper_ics.pdf (accessed on 20 October 2017).

Rompotis, Gerasimos Georgiou. 2009. Active Versus Passive Management: New Evidence from Exchange Traded Funds. Available online: http:/ / ssrn.com/abstract=1337708 (accessed on 28 October 2017).

Sharpe, William F. 1966. Mutual Fund Performance. Journal of Business 1: 119-38. [CrossRef]

Statista. 2017. Number of Regulated Open-End Funds Worldwide from 2008 to 2016. Available online: https: / / www.statista.com/statistics/630524/number-of-regulated-open-end-funds-worldwide/ (accessed on 26 September 2017).

Sultan, Galib. 2014. A Study on Bond Exchange-Traded Funds (ETFs) and Corporate Bond Liquidity. Available online: http://www.lyxor.com/fileadmin/user_upload/pdf/3-ETFs_AND_CORPORATE_ BOND_LIQUIDITY-WP.pdf (accessed on 26 September 2017).

Svetina, Marko. 2010. Exchange traded funds: Performance and competition. Journal of Applied Finance 20: 130-45. [CrossRef]

Tofallis, Chris. 2008. Investment volatility: A critique of standard beta estimation and a simple way forward. European Journal of Operational Research 184: 1358-67. [CrossRef]

Turskis, Zenonas, Simona Dzitac, Aušra Stankiuviene, and Ritoldas Šukys. 2019. A Fuzzy Group Decision-making Model for Determining the Most Influential Persons in the Sustainable Prevention of Accidents in the Construction SMEs. International Journal of Computers, Communications \& Control 14: 90-106.

Zavadskas, Edmundas Kazimieras, Artūras Kaklauskas, Darius Kalibatas, Zenonas Turskis, Mindaugas Krutinis, and Lina Bartkienè. 2018. Applying the Topsis-F method to assess air pollution in vilnius. Environmental Engineering \& Management Journal (EEMJ) 17: 2041-50.

Zeng, Shouzhen, and Yao Xiao. 2018. A method based on TOPSIS and distance measures for hesitant fuzzy multiple attribute decision making. Technological and Economic Development of Economy 24: 969-83. [CrossRef]

(C) 2019 by the authors. Licensee MDPI, Basel, Switzerland. This article is an open access article distributed under the terms and conditions of the Creative Commons Attribution (CC BY) license (http:/ / creativecommons.org/licenses/by/4.0/). 